\title{
Development and Intellectual Property Construction of Internet of Things
}

\author{
Shu Yuan \\ Wuhan University of Technology, Wuhan 430070, China \\ shuyuan1212@163.com
}

Keywords: Internet of Things; Intellectual property; Legal protection.

\begin{abstract}
Internet of Things has an inseparable relationship with intellectual property law as high and new technology. The intellectual property law for IOT has relationship with the future development of IOT. Countering the shortcomings of the protection in our country, this thesis use the methods of statistics and comparative analysis to finding problems about IOT intellectual property legal protection, and putting forward the improvement suggestions.
\end{abstract}

\section{Introduction}

The Internet of Things (IOT) is booming around the world. It is being hailed as a "science and technology" which change people's life and our world after the Internet. Our country attaches importance to the development of the Internet of things very early in order to striving for dominant position. But from the development of IOT, it is still in its initial stage. The key of technical change is innovation in the development of IOT. We must encourage the technological innovation and give enough attention to the legal protection of intellectual property rights, then we can build good development trend of IOT in the future. Intellectual property law play a key role in protecting high and new technology and it has become a big countries' economic or political policy to the protection of intellectual property rights. Intellectual property law in our country enacts very late and the institution of intellectual property right property has not been widely implemented. Around the worldwide, compared with the United States, Japan, etc, our technology power protection is weak. Now the Internet of things has become a key area to the world in new round of development and it must be one of the focuses of protection of the Internet of things about the intellectual property right protection of the national IOT strategy in the future. So we should build the overall layout of the Internet of things and breakthrough technology difficulties and find the shortage of intellectual property right protection of Internet of Things in our country. Finally we can achieve the rapid development of Internet of things.

\section{The Culture of Internet of Things Intellectual Property Right and Legal System}

Intellectual property culture is a kind of advanced culture, in China is in the enlightenment and cultivation stage, this stage is very fragile and special, many phenomena perplexing. Therefore, the general understanding of intellectual property culture is better than in a narrow sense, and also conducive to the development of intellectual property culture. In China, the culture of intellectual property right and the legal system of intellectual property rights is accompanying. Intellectual Property Law refers to collectively regulate social relations caused by intellectual creation activities. From a legal point of view, the force of law reflected in the regulation of force on people's behavior, the behavior caused, change and termination of legal relationship, behind the law reflects the legislators expect in the legal system and the ideal order, select the should be made to the public proper behavior. the existing problems in protection of Internet of things intellectual property law in our country: Limited legal consciousness and weak groups' protection; Limitation in applying for object of patent and lacking the ownership of patent's application; The secrets of the trademark infringement but unknown web site tort standard; the lack of special laws, the low specification level. 


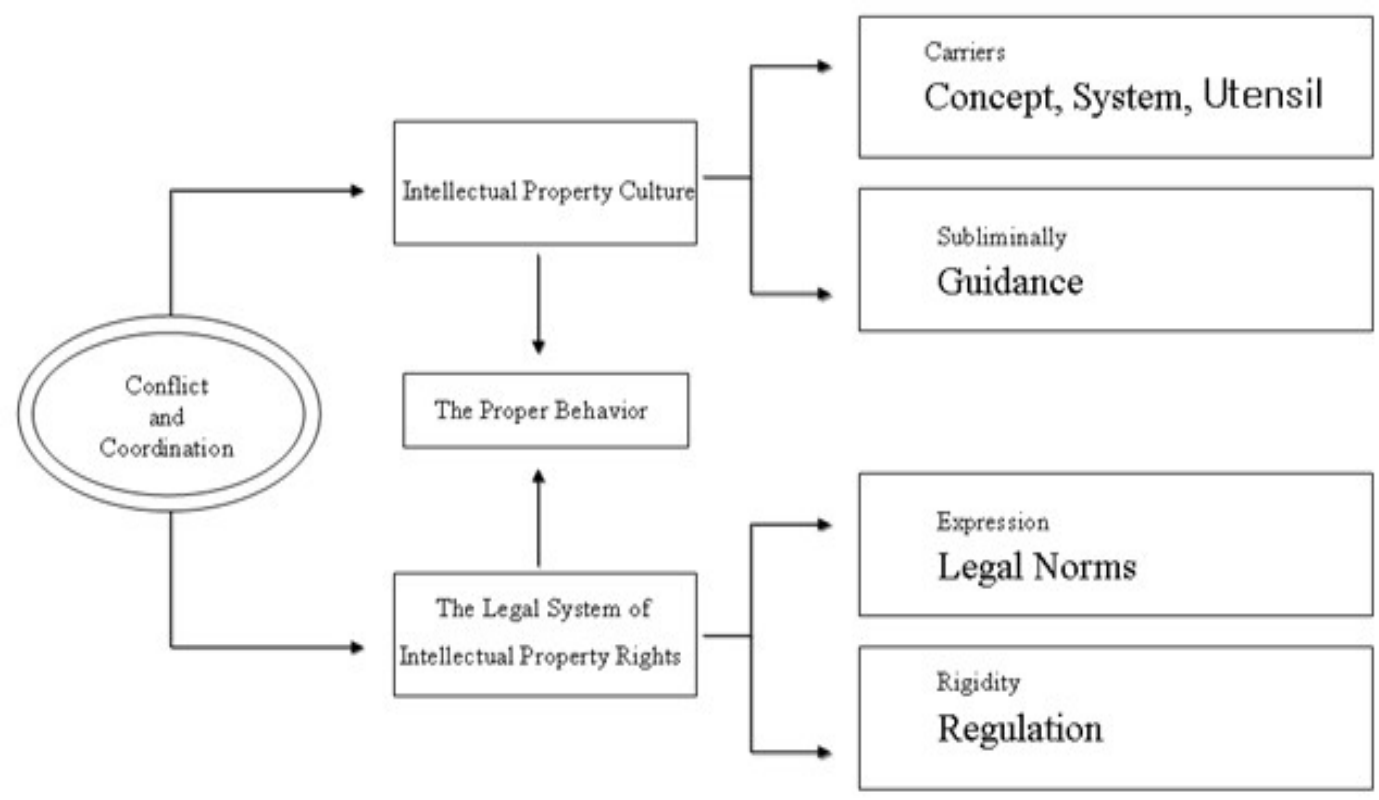

Fig. 1.The Mechanism of Intellectual Property Culture and Intellectual Property Legal System

As the figure 1 shows the different mechanisms about intellectual property culture and the intellectual property legal system. From a cultural point of view, consciousness is the core of the culture, it is influence character by environment leads and infiltration affect attitudes people's ways of thinking and behavior, and guide people's behavior habits and patterns, and accepted by the general public. So the author advocates, intellectual property culture refers to human generated in the creation, use, protection, management, and other intellectual property rights related activities, all the spiritual concept of the impact of the development of intellectual property rights, and the cultural connotation of the intellectual property system and the material achievement reflects the value. The construction of Internet of thing intellectual property culture is an important part of the sustainable development strategy.

\section{Punitive Damages Legal Sources in China}

China first in the "Consumer Protection Law" enacted in 1993, Article 49 of the punitive damages, which states that "operators to provide goods or services fraud, consumers should be increased in accordance with the requirements of the compensation for losses, increase the amount of compensation cost for consumers to purchase goods or services received twice the cost. " In addition, the "Contract Law" Article 113 be confirmed, states: "operator to provide goods or services to the consumer fraud, and in accordance with the People's Republic of China Consumer Protection Law." so China's punitive damages in the civil realm is the first case in the contract to begin limited applicable. In 2003 the Supreme Court "to hear real estate contract disputes interpretation of the law applicable to certain issues" and in 2009 promulgated the "Food Safety Law" were made to the provisions of punitive damages. The "Food Safety Law" second paragraph of Article 96 states: "The production does not meet the food safety standards of food, or knowingly selling do not meet the food safety standards of food, consumers in addition to a claim for damages, but also may apply to producer or seller to pay the price demanded compensation tenfold. " The Chinese make clear the introduction of punitive damages in the field of tort law, enacted in 2009, "Tort Liability Act," Article 47 states: "knowing that the product is still defective production, sales, resulting in death or serious harm to health has been infringed is entitled to request the appropriate punitive damages. "law explicitly included in the scope of punitive damages in product liability, this provision is significant. 


\section{Theoretical and Practical Foundation of Introducing Punitive Damages Liability}

The field of intellectual property introduced punitive damages is the demand of the law. China to pay damages for infringement of intellectual property rights is mainly based on actual losses, the illegal profits of the infringer, "fee for use of intellectual property rights have been violated or transfer fees are fair and reasonable," as well as statutory damages, which have successively four bits the method to determine the sequence. Statutory compensation of intellectual property is an academic penalty for a generalized method of compensation, usually thought to refer to the aforementioned three methods are proving unable to identify or determine the "people's court at the request of a party or on its statutory compensation system to determine a specific amount of damages or the amount of the magnitude of the base amount." statutory compensation be seen not as a punitive damages, not simply that a provision to protect the rights of persons or tendentious" last resort" may cause the infringer to bear the liability exceeds the cause of the damage suffered by the right holder, such provisions will be included as punitive damages. Statutory compensation is still a "last resort extension made" the right to compensation for the damages suffered for the purpose of calculation of the amount of compensation. It largely depends on the discretion of the judge. In addition, some scholars proposed statutory compensation field of intellectual property does not require total compensation unit, there is no clear onus is likely to cause a waste of judicial resources and Judge arbitrary.

We excluded 29 cases involving ownership dispute, the court dismissed the plaintiff referee infringement lawsuit, the focus of non-contentious cases involving infringement damages. In some cases, the cost of the necessary and reasonable expenses also included the amount of compensation being. These IPR infringement cases, 13 cases of first instance cases, 41 cases of second instance case, the retrial case two cases, one case arraigned case. As shown in fig 2. In some of the cases of first instance verdict, the court claims damages for the plaintiff's support rate is significantly higher than the second instance verdict. The plaintiff's damages on "expectations" there is widespread too high, resulting in a waste entering the second instance of litigation costs, and the final result to be in full support of the following situations: First, there is sufficient evidence of actual loss is calculated based on clear ; the second, according to the contract entered into by the parties in advance; thirdly, infringement subjective malice obvious infringement plot is extremely serious, long duration, affecting a wide range of profitable huge infringement has far exceeded the plaintiff's request for damages ; fourth, the plaintiff and the defendant lost profits are difficult to calculate, the court combined with the provisions of relevant laws and regulations, discretionary compensation based on the actual situation of the case. In addition to the case, the author access to relevant information, for "compensation for the plaintiff's request for a similar amount in case precedents to support the judgment" .the court may also make a request for the full support of the plaintiff's verdict.

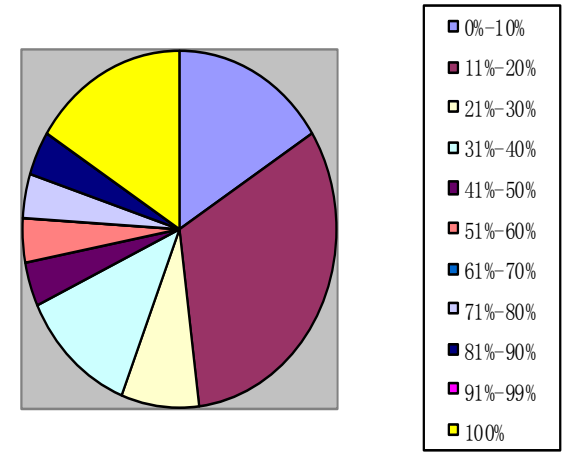

Fig. 2 The Proportion of the Amount of Damages the Plaintiff on the Lawsuit and Court Decisions

As can be seen from the above cases, it is clear that the presence of defects, on the one hand, intellectual property infringement damages calculated on the standard scale endless unity, sweeping discretionary compensation increases the penalty operational difficulty. Some scholars worry about this situation which led to duplication of compensation through a variety of ways to prosecute prone. On the other hand, with the field of intellectual property infringement diverse types of complex, a 
wrongful act may cover a variety of intellectual property rights violations, the actual economic losses and profits not only difficult to clear the infringement, but the loss suffered by the infringer more fat difficult to measure the physical, intellectual property infringement brought some broad social impact of long-term and severe.

\section{Conclusion}

The actual situation of the protection of intellectual property law of our country Internet of things, bases on the analysis above, proposed suggestions to consummating our country's Internet of intellectual property protection: strengthen the advertising, attaches great importance to the protection groups; Bringing a standard into the protection of the intellectual property law, perfecting the scope of the patents; Clear standards of infringement of network, Finally consummating special law of about Internet in our country.

\section{Reference}

[1] Yang Zhushun, Liu Jieming. The Formation Mechanism of Enterprise Intellectual Property Culture, Construction of Intellectual Property Culture and Development Forum. (2013) 277.

[2] Rolf H.Weber.Internet of Things-New security and privacy challenges.Computer Law and Security Review: The International Journal of Technology and Practice, 2010, 26(1):23-30.

[3] Cui Zhen, Discussion on Intellectual Property Punitive Damages System, Fudan University Master Thesis. (2011) 33.

[4] Burgelman R, Maidique A. Strategic Management of Technology and Innovation, New York: McGraw-Hill, 2004.

[5] Liang Tang. China's Internet industry development present situation and the industry chain analysis [D]. Beijing university of posts and telecommunications, 2010. 